\title{
Reference control in the narratives of adult sign language learners
}

International Journal of Bilingualism

(C) The Author(s) 2014 Reprints and permissions: sagepub.co.uk/journalsPermissions.nav DOI: $10.1|77 /| 3670069|4527| 86$ ljb.sagepub.com

\author{
Aurora Bel \\ Universitat Pompeu Fabra \\ Marta Ortells \\ Universitat Pompeu Fabra

\section{Gary Morgan} \\ City University London
}

\begin{abstract}
Aims and Objectives: Learning to control reference in narratives is a major step in becoming a speaker of a second language, including a signed language. Previous research describes the pragmatic and cognitive mechanisms that are used for reference control and it is clear that differences are apparent between first and second language speakers. However, some debate exists about the reasons for second language learners' tendency for over-redundancy in reference forms especially in the use of pronouns. In this study we tested these proposed reasons for L2 differences.

Methodology: Narratives by II native signers and I 3 adult advanced-learners of Catalan sign language were analysed for person reference.

Data: Analysis focused on forms for introduction, reintroduction and maintenance of characters. Findings: The results indicate both groups used reference forms according to information saliency principles in similar ways. Differences between the groups were in the use of pronominal signs, where the learners adopted an over-redundancy strategy in line with one hypothesis in the previous studies on second language acquisition in spoken languages.

Significance: The results are discussed in terms of the vulnerable syntax-pragmatics interface in developing bilinguals
\end{abstract}

\section{Keywords}

Catalan Sign Language (LSC), discourse organisation, reference, second language acquisition, interfaces 
Mature command of a language is more than the coordination of vocabulary and syntax. Once learners start to build connected sentences in narratives they begin to enter into the more complex areas of their second language acquisition. Fluent speakers easily manage person reference across sentences in narratives through the selection of nouns, verbs and pronouns for differing pragmatic functions. This coordination of forms is seen in narrative retells from the picture book 'the frog story' (Berman \& Slobin, 1994). Research using story retelling elicitation methods such as the frog story has shown that this level of language control is demanding for both first (child) and adult second language learners (Strömqvist \&Verhoeven, 2004). In second language (L2) acquisition, speakers have to master the range of language devices that exist in the target language to introduce, maintain and reintroduce referents into discourse, and some of these devices may not have counterparts in their first language. They also have to identify the pragmatic contexts which trigger each device (Givón, 1983). Such cross-linguistic differences are no more radical than in the case of adult L2 learners of signed languages.

Signed languages have all the levels of complexity and expressive power of spoken languages, including phonological and semantic-morphological levels (Sandler \& Lillo-Martin, 2006; Stokoe, 1960). In addition, they are processed in similar but not identical ways in cognitive and related brain networks (Emmorey, 2002; MacSweeney, Capek, Campbell, \& Woll, 2008) and they are acquired as first languages by children following mostly the same developmental stages as those identified for spoken language (Chamberlain, Morford, \& Mayberry, 2000; Morgan \& Woll, 2002; Petitto, 1997). The level of linguistic organization we investigated in the current study was discourse. As in spoken languages, this type of language relies on pragmatics and coordination of several linguistic forms. In contrast to the linear sequence of words in the previous frog story example, fluent users of sign languages such as British Sign Language (BSL) or Catalan Sign Language (LSC) direct points and movements of signs between locations in a visual sign space in front of the torso to coordinate reference across sentences (Barberà, 2010, 2012; Emmorey \& Falgier, 1999; Gee \& Kegl, 1983; Metzger, 1994; Morgan, 2005). How these devices are used will be described in the following sections.

There is relatively little psycholinguistic research on LSC (Barberà, 2012; Baus, GutiérrezSigut, Quer, \& Carreiras, 2008) and in general on L2 acquisition of any signed languages. The current study investigates how hearing adult learners of LSC use referential devices to establish and maintain reference in narratives compared with deaf native L1 signers. We are interested in how signed narratives are organized at the pragmatic level of person reference across sentences, and what differences if any there will be between L1 and L2 signers. In our study, the L2 learners are facing two challenges: (1) the difficulties that L2 learners, in general, encounter in acquiring the linguistic forms and their corresponding discourse functions, and (2) the problems derived from perceiving and producing these devices in a different physical modality - the manual-visual modality of sign languages - compared to the audio-vocal modality of their L1 spoken languages. This research can tell us more about the linguistic organization of reference in general. It can also allow us to evaluate psycholinguistic theories of L2 acquisition by examining the unique case of developing bimodal bilinguals (hearing people in the later stages of sign language acquisition).

\section{The role of reference forms in narrative discourse}

Different linguistic theories posit pragmatic constraints in the use of reference forms across sentences. These revolve around the notions of salience and topic, e.g. a topicality hierarchy (Givón, 1983), accessibility theory (Ariel, 1990, 2001) and centring theory (Gordon, Grosz, \& Gilliom, 1993). Most research focuses on the nominal and pronominal categories. Together with other markers, nominals and pronominals act as cohesion devices and contribute to narrative 
organization. In broad terms, a pronoun (e.g. ' $h e$ ') is likely to be interpreted as denoting an entity that has already been introduced by a salient category (e.g. a nominal such as 'the boy'). Conversely, nominal categories are used to refer to less salient or less accessible referents in the narrative. Further, speakers tend to use pronouns to refer to a prominent or salient entity, e.g. human agents over non-human (Garvey, Caramazza, \& Yates, 1976). Pronominal elements are also sensitive to other factors such as gender, order of presentation (Arnold, Eisenband, Brown-Schmidt, \& Trueswell, 2000; Trueswell, Papafragou, \& Choi, 2011) and the syntactic function of the antecedent (Carminati, 2002).

In studies of L1 acquisition, children quickly acquire the patterns of their native spoken language, but full development of narrative skills and the ability to introduce and maintain referents cohesively across stretches of sentences continues throughout childhood (e.g. Hickmann, 2004), particularly for anaphoric pronouns (Shin \& Cairns, 2012). This extended development is due to children's growing awareness of which linguistic forms should be used according to their addressee needs. This development is intertwined with pragmatic awareness of referential choices, metalinguistic skills and theory of mind. Narrative also requires the coordination of other cognitive abilities linked to memory, information processing and the understating of abstract concepts (e.g. Berman \& Slobin, 1994; Hendriks, Kosters, \& Hoeks, 2013).

In contrast, L2 acquisition of narrative follows a different path, as adult speakers already have a fully acquired system of referential choices in their L1 to draw upon in their learning and greater general cognitive abilities (Montanari, 2002; Strömqvist \& Day, 1989). However, they may transfer some linguistic elements from their L1 (Hendriks, 2005; see also Jarvis \& Pavlenko, 2008 for a general approach to transfer). Therefore, L2 learners are also influenced by the specific patterns of reference forms used in their L1 narratives. The level of positive or negative transfer is modulated by the linguistic closeness between the two languages. This is in relation to a specific feature property - for example, Italian and Catalan are close, as they are both null-subject languages that have two pronouns (null and overt) and German and Spanish are distant as German is a non-null-subject language and hence excludes the possibility of null pronouns. Regardless of language proximity, when morphosyntax interacts with discourse pragmatics - the so-called syntax-discourse interface - this has been shown to be vulnerable in bilingualism and difficult to acquire in L2 learning (Müller \& Hulk, 2001; Serratrice, 2006; Tsimpli, Sorace, Heycock, \& Filiaci, 2004). More specifically, this has been formulated under the Interface Hypothesis (IH) which predicts better performance in syntax than in the syntax-discourse interface (see Sorace, 2011 for a general view).

This vulnerability is characterized by instability and optionality in production, as well as in comprehension. For instance, bilinguals and L2 learners even with a native-like command of the target language accept and produce overt subjects in a null-subject language in contexts where monolinguals would not have admitted or produced them. For example in Spanish, 'después de levantarse, él bajó las escaleras' ('after he woke up he went downstairs'), instead of the target null element 'después de levantarse, $\varnothing$ bajó las escaleras' ('after he woke up, $\varnothing$ went downstairs'). In studies where L2 learners of Spanish or Catalan are English speakers - recall that English, as a non-null-subject language, has only overt pronouns - the logical reasoning is to ascribe the overextension of overt pronouns to language transfer from English (Pérez-Leroux \& Glass, 1999).

What is particularly interesting is that this pattern persists in the acquisition of L2 pronouns between two null-subject languages (Lozano, 2006; Margaza \& Bel, 2006; Montrul, 2004; Sorace $\&$ Filiaci, 2006). Sorace, Serratrice, Filiaci, and Baldo (2009) have termed this general property of L2 discourse as over-redundancy. Over-redundancy is not only a feature of L2 speakers, it is also attested among monolinguals, albeit to a lesser extent than L2 learners and bilinguals. In fact, monolingual native speakers of null-subject languages do occasionally accept redundant overt 
pronouns. This has been shown experimentally by Carminati (2002), but also in the behaviour of the control groups in Sorace and Filiaci (2006) and Tsimpli et al. (2004).

Sorace et al. (2009), Bel, Perera, and Salas (2010) and García-Alcaraz and Bel (2011) proposed that this over-redundancy reflects the instability of overt pronouns in the production of L2 speakers and is manifested as optionality. More specifically, Sorace and Serratrice (2009) and Sorace (2011) refer to a cognitive disadvantage in processing anaphoric forms in L2 speakers that leads to the use of overt pronouns as a compensatory strategy. Thus, bilinguals and L2 speakers use overt subject pronouns as a compensatory strategy to offset online processing demands (Sorace et al., 2009) when constructing large units of language, such as connected narratives. This selective difficulty of overt pronouns thus provides language users with easier processing resources to implement discourse operations efficiently, even when ambiguity is not at stake and when their use entails redundancy.

In contrast to spoken languages, the interface between discourse pragmatics and morphosyntax has not received much attention in sign languages. Only very recently Lillo-Martin and Quadros (2011) have addressed the acquisition of what they term role-shift. This discourse device is also labelled 'constructed action' in the literature and allows signers to report perspective-taking. It is identified as an interface phenomenon among children acquiring American Sign Language (ASL) and Brazilian Sign Language. The slow development in these languages by native signing children gives support to the IH. Thus, the over-redundancy proposal has up to this point not been tested with L2 learners of a signed language, highlighting the novelty of this study.

The study of narrative cohesion and reference control for the most part has focused on spoken languages, yet discoveries over the past three decades in the linguistics of signed languages used by deaf communities reveal they have the full set of linguistic devices of any natural language (e.g. Emmorey, 2002; Klima \& Bellugi, 1979; Quer, 2011a). Less has been documented about the pragmatic constraints used in sign language narrative, and so by looking at narrative production in adult L1 signers we can contribute to the understanding of sign languages, as well as investigate developing bimodal bilingualism in hearing L2 learners of sign languages. While English and Italian L1 speakers overuse pronouns alike when speaking a second spoken language, we ask what will speakers of L1 null-subject languages do when learning Catalan Sign Language (LSC)? If transfer also affects the discourse level (Jarvis \& Pavlenko, 2008), these learners would use a transfer strategy and export the L1 referential devices used to track referents in L1 narratives into narratives in sign language. This is unless the cognitive strategy proposed by Sorace et al. (2009) is used by L2 learners across language modalities.

In children's L1 acquisition of sign narratives, similar general milestones as those for spoken language development have been documented (Chamberlain et al., 2000; Morgan \& Woll, 2002; Schick, Marshark, \& Spencer, 2006). The study of hearing people's acquisition of sign language (extending the notion of bimodal bilingualism to users of a spoken language and a sign language) is a growing research area (e.g. Casey \& Emmorey, 2009; Emmorey, Petrich, \& Gollan, 2012; Pyers \& Emmorey, 2008). Most of this research entails subjects who are the hearing children of deaf signing parents and become adult bimodal bilinguals. There is very little research on the topic of developing L2 signers. In the current research we ask if L2 signers will pattern like L2 spoken language learners in the domain of referential pragmatics.

\section{The structure of sign language narratives}

There are two ways signers relay information about referents in narratives: (1) non-manual features (facial expressions or head and body position, which add to or modify the meaning of manual signs) and (2) manual signs introduced into the discourse with lexical items, as well as signs with 


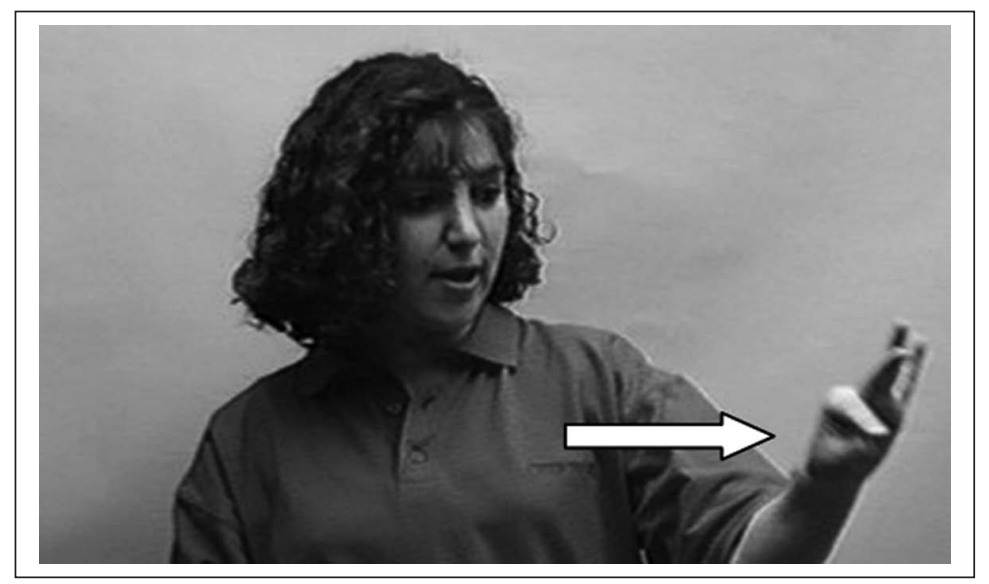

Figure I. Agreement verb 'he asks her'.

specific locations in the sign space. This means further mentions of a given referent can be anchored to these spatial locations. The devices used for the establishment of reference in sign language narrative production we study in this research come from only the manual reference types and are: nominal signs (e.g. BOY, FROG, DOG etc.), points to locations in the space in front of the signer which function as pronominals, morphological markers of verb agreement and a device, more prevalent in signed than spoken languages, known as entity classifiers. We describe each of these linguistic devices briefly (for more details see Sutton-Spence \& Woll, 1999; and Quer, 2011a, 2011b. See also Barberà, 2012 for an in depth discussion of pronominal elements and the use of space in LSC).

There are other devices available to signers in narratives for assigning discourse prominence, such as role shifts, which mark a displacement to a first person signalled by changes in facial expression, eye-gaze direction or body position (Morgan \& Woll, 2003; Wilbur, 1994). Facial expressions, head and body position, which play a somewhat analogous function to prosody and intonation in spoken languages, encode discourse properties such as focus or topic informative functions (Morales-López, Reigosa-Varela, \& Bobillo-García, 2012). Since in our study we focus on referents that are spatially established and on third-person anaphoric entities only (neither the signer nor the addressee), role shift constructions were outside the scope of our analysis and so this set of non-manual articulators are not addressed further here.

Returning to the manual signs in more detail, there are three different kinds of verbs in BSL, LSC and other sign languages - agreement verbs (e.g. TO-GIVE), spatial verbs (e.g. TO-CARRY) and plain verbs (e.g. TO-LIKE). Some authors, however, consider that a twofold division would best be used to characterize verbs, grouping spatial and agreement verbs in a single category (Quer, 2011b for LSC and Quadros, 1999 for Brazilian Sign Language).

Agreement verbs are directional verbs which can be moved through the signing space in front of the torso to indicate the 1st, 2nd or 3rd person. In Figure 1 the agreement verb TO-ASK in BSL moves between two locations on the right and left side of space, previously assigned as referring to a man and a woman. Thus, the meaning of the inflected verb is 'he asks her'. If the sign moved in the opposite direction the meaning would be reversed, i.e. it would be the woman who gives something to the man. Similar constructions are used in LSC (Quer, 2011b).

The use of verb inflections allow the interlocutor to understand who is doing what to whom by recalling the previous use of sign space. Verb inflections incorporate person and number agreement 
features that allow the use of null referring expressions (i.e. null pronouns), as well as overt expressions, such as pointing signs (i.e. overt pronouns), nominals, etc. When referents need to be maintained in these spatial locations across sentences or events, both signer and his/her interlocutor have to keep spatial references primed in working memory (Emmorey, Norman, \& O'Grady, 1991). While spatial locations are unique to sign language narratives, the cognitive-pragmatic resources involved in monitoring these across a narrative might be the same as those required for pronominal reference in spoken language (Barberà, 2012; Emmorey \& Falgier, 2004; Emmorey, Tversky, \& Taylor, 2000; Perniss, 2012).

Spatial verbs in LSC use the signing space and move between locations associated with objects or people. As with agreement verbs, these arguments can include indexical/pointing signs (i.e. overt pronouns), lexical nominals and classifiers. There is an additional pronominal element: the sign PERSON, which only denotes human referents and can co-appear with the determiner MATEIX ('same'); it can also be used as a noun. Lexical nominals are noun phrases, finger spelt proper names, etc. Entity classifiers are a set of handshapes that refer to a semantic group of referents with perceptual similarities (e.g. long thin referents: pencils, people, flagpoles, etc.). These handshapes can be combined with particular movements or positions of the hands in order to express path and locative information (see Emmorey, 2003; Morgan \& Woll, 2007). The semantic figure is expressed by the classifier handshape that represent classes of referents. As each object is mentioned, the noun is articulated first, followed by a corresponding classifier handshape located in the space in front of the signer. The path and/or motion is shown by the movement of the hand or relative location. Other information can be encoded on the verb such as manner, orientation and simultaneity.

Pronouns, like agreement verbs, point out a location previously assigned to a referent located in sign space and classifiers encode the location or movement of a class of nouns (e.g. people, vehicles, animals) between or at these locations. The interpretation of pronouns is dependent on previous overt reference and setting up of referential locations. Classifiers are therefore anaphoric, but interestingly, they pick out the referent and its location in space simultaneously (Emmorey \& Falgier, 1999).

Plain verbs, the last category, are not directed towards spatial locations (e.g. TO KNOW) and so some authors have suggested that null-subject pronouns must be identified with a topic (LilloMartin, 1986).

\section{The present study: research questions}

Returning to the question of how signers or speakers manage reference choice, in the saliencytopicality literature, for spoken language (e.g. Hendriks et al., 2013), it is known that the semantic content of a referring expression is to some extent connected to the particular contexts where they are expressed. Up to this point we have posited that different anaphoric expressions exhibit different preferences for discourse functions. The three functions we concentrated on in the present study are: reference introduction, reintroduction and maintenance. In languages such as Spanish, Catalan, or Italian, which have two different forms of pronouns, null pronouns realize referent maintenance and overt pronouns tend to express referent reintroduction. Lastly, nominal categories usually convey referent introduction, as well as reintroduction. Since LSC includes different (pro) nominal categories, we first ask whether they display these same preferences. Our working hypothesis, derived from prior research with spoken languages that allow null subjects and have null and overt pronouns, is that a null third-person pronoun in subject position tends to express a discourse topic that has been introduced or mentioned in the previous sentence. Also, an overt pronoun in subject position tends to reintroduce a discourse topic or change the topic reference of the previous sentence. 
In summary, we aim to document the different roles of referring expressions in the narratives of both L1 and L2 users of LSC, thus providing baselines on this sign language, as well as document language use in developing bilinguals. A comparison of these two types of signers will enable us to ask questions about the general properties of narrative in both signed and spoken language, as well as evaluate the over-redundancy explanation of L1 and L2 differences by testing this hypothesis with signed L2 acquisition. Our hypotheses are:

1. Referential devices used by first language adult signers for expressing discourse functions such as introduction, maintenance and reintroduction are specialized in LSC production, and can be predicted by the saliency-topicality literature.

2. Second language signers (L2) will display differences in their choice of referential forms as predicted by the interface hypothesis. Specifically, there will be more redundant use of pronominal reference in the L2 signers compared with the L1 group.

\section{Method}

\section{Participants}

The deaf signer sample (termed L1 signers) consisted of 11 deaf adults (five female, six male). Five had deaf parents and the other six were exposed to LSC before age five, and thus were considered to be native signers or native-like (following Cormier, Schembri, Vinson \& Orfanidou, 2008). Deaf participants also had knowledge of both written Spanish and Catalan. The mean age of the deaf group was 32.4 years (range: 20-52 years). The sign language learners (termed L2 signers) consisted of 13 hearing adults (11 female) who were bilingual speakers of Catalan and Spanish, mean age 25.6 (range: 18-33 years) in their final year of sign language interpreter training. They were assessed to be at an advanced level by native signers in their training courses, with 600 hours of formal exposure to LSC. None of the L2 group had deaf parents.

\section{Procedure}

Using the method devised by Berman (2008), both L1 and L2 participants individually viewed a three-minute silent film about conflicts at school and subsequently were instructed to tell a new story to video camera about a similar experience they knew about involving a friend or classmate during their childhood or teenage years. This instruction was devised to induce participants to introduce different third-person characters in their production. It also promoted the use of different spatial locations to refer to them in introductions, reintroductions and reference maintenance via sign pronouns, agreement verbs, classifiers or other referential devices. As a consequence of the instruction given, signers made a prolific use of third-person referents and rarely made reference to first and second person except for role shift constructions. Remember that these constructions were excluded from the analysis for the reasons given above.

\section{Coding and analysis}

All signed stories were video recorded, transcribed and analysed by two trained and fluent LSC signers who worked as professional interpreters. Narratives were coded using the ELAN annotation tool (Brugman \& Russel, 2004) for reference categories, discourse functions and number of utterances. An utterance was defined as a main clause and all its subordinate clauses, and a clause as a segment that contains a predicate. Coordinate clauses were transcribed as separate utterances. 
Utterances that were not interpretable were classified as unclear. We used different tiers in our transcription: a gloss notation for sign sentences, all manual signs (one tier for the active hand and another for the non-active hand) and non-manual features such as eye-gaze and other parts of the body. As for eye-gaze, there is a debate as to whether this facial feature marks definiteness contrasts (Tang \& Sze, 2002, for Hong Kong SL), is an abstract agreement feature (Neidle, Kegl, MacLaughlin, Bahan, \& Lee, 2000, for ASL), helps to support person distinctions (Thompson, Emmorey, \& Kluender, 2006, for ASL; Meurant, 2008, for Southern Belgium SL) or marks role shift (Morgan \& Woll, 2003, for BSL). Since we are concerned with only third-person subjects, we restricted our analysis to just the manual articulators. In addition, in LSC eye-gaze is a localization device that usually coincides with the corresponding manual element (Barberà, 2012, p. 90). Finally, two more tiers, one for category type and one for discourse function (introduction, reintroduction etc.), were included. Examples of coding are provided in Appendix 1.

We focused on utterances in which the signer was not the protagonist of the narrated event (i.e. not first person references); recall that role shift constructions were not coded because they do not denote discourse referents placed in the signing space. After identifying these utterances, all thirdperson elements in subject position were coded for reference category and discourse function. The four categories were 1. nominal expressions (e.g. noun phrases, names and finger spelling); 2. overt pronominal expressions (pronoun points and the sign meaning PERSON, with or without the determiner MATEIX, 'same'); 3. null pronominal expressions (plain verbs with subject ellipsis and agreement verbs which marked person morphologically) and 4. classifiers.

In addition to reference category, referring expressions in subject position were coded for discourse function following the scheme used by Bamberg and Marchman (1991). We coded a referring expression as reference introduction the first time that a referent was mentioned in the narrative, as reference reintroduction in contexts where the topic referent shifted between two adjacent sentences, and reference maintenance in contexts where the topic referent was the same as in the previous sentence. For inter-rater reliability, two independent coders transcribed $17 \%$ of the narratives of the L1 and L2 groups, corresponding to four full transcriptions (two L1 and two L2). For the L1 group, Cohen's kappa was $\kappa=0.898(p<.001)$ for discourse functions and for the L2 group, the result was $\kappa=1.000(p<.001)$.

\section{Results}

After excluding utterances not containing third-person referents in subject position, coding produced a total of 417 utterances across L1 and L2 groups $(\mathrm{L} 1=184, \mathrm{~L} 2=233)$. This represented approximately $65 \%$ of the total number of utterances in the corpus. It is worth remembering that participants were asked explicitly to tell a story that happened to a third person. The number of utterances produced in the narratives (i.e. length) varied between subjects in both groups (L1 = 9-53, L2 = 9-49 utterances). Our first analysis of the structure of the narratives concerned the overall distribution of referring expressions in third-person subject position in both group's narratives. This is shown in Table 1.

From this analysis it can be seen that in both the L1 and L2 groups, the vast majority of reference forms were overt elements (nominals and overt pronouns), and conversely, null pronouns and classifiers were relatively low. Because there are a lot of full expressions (i.e. nominals and overt pronominals) and few null expressions the narratives were thus referentially explicit. We will return to this explicitness in the discussion. Next we analysed whether there were any differences between L1 and L2 groups in use of reference forms. A two-way independent group chisquare indicated that there were differences between groups in the choice of the different referring expressions $\left(\chi^{2}=15.25\right.$, df $=3, p=.0016$, Cramer's V $\left.=0.1912\right)$. Four independent-samples 
Table I. Distribution of referring expressions by group.

\begin{tabular}{|c|c|c|c|c|c|c|}
\hline Group & & $\begin{array}{l}\text { Total } \\
\text { utterances } \\
\text { with a third } \\
\text { person subject }\end{array}$ & $\begin{array}{l}\text { Nominal } \\
\text { elements }\end{array}$ & $\begin{array}{l}\text { Overt } \\
\text { pronouns }\end{array}$ & $\begin{array}{l}\text { Null } \\
\text { pronouns }\end{array}$ & Classifiers \\
\hline LI & $\begin{array}{l}N \\
\% \\
S D\end{array}$ & 184 & $\begin{array}{l}82 \\
44.57 \\
19.16\end{array}$ & $\begin{array}{l}57 \\
30.98 \\
17.85\end{array}$ & $\begin{array}{l}35 \\
19.02 \\
21.52\end{array}$ & $\begin{array}{l}10 \\
5.43 \\
6.39\end{array}$ \\
\hline L2 & $\begin{array}{l}N \\
\% \\
S D\end{array}$ & 233 & $\begin{array}{l}100 \\
42.92 \\
15.13\end{array}$ & $\begin{array}{l}105 \\
45.06 \\
18.52\end{array}$ & $\begin{array}{c}19 \\
8.15 \\
10.89\end{array}$ & $\begin{array}{l}9 \\
3.86 \\
4.47\end{array}$ \\
\hline
\end{tabular}

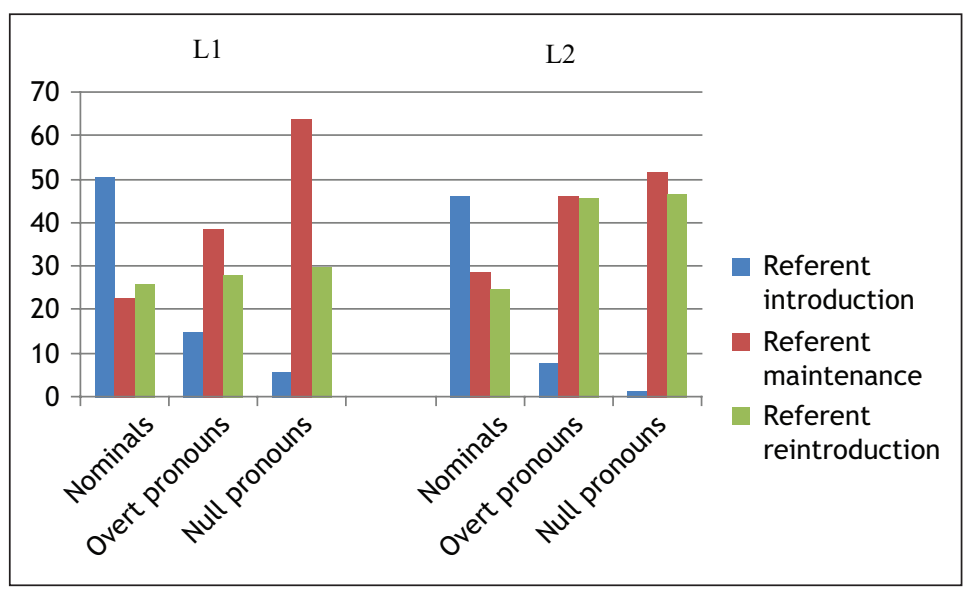

Figure 2. Distribution of reference forms by reference functions in both LI and L2 groups as percentages.

$t$-tests - one for each type of referring expression - were conducted on the arcsine-transformed percentages to identify specific differences between groups. There were no differences between groups for use of nominal elements and classifiers, but the L2 group had higher use of overt pronouns $(t(22)=-2.21 ; p=.037)$ as well as lower use of null pronouns $(t(22)=2.14 ; p=.043)$ than the L1 group. As we predicted, therefore, the L2 group was more explicit than L1 signers in their use of reference forms.

Our next question concerned which reference forms were used for which discourse functions in both groups. As the number of classifiers used in both groups was very low we omitted these from the following analyses. We divided reference expressions by discourse function and compared proportionally (percentage of total) the different forms by each function. Figure 2 shows the proportional distribution of referring expressions for each discourse function by group in percentages.

From Figure 2 we see that both groups preferred nominal expressions for referent introduction and overt pronouns for referent maintenance and referent reintroduction in similar proportions. Differences appeared between groups in the distribution of null pronouns. Whereas the L1 group clearly associate null pronouns with maintenance, the L2 group divides these minimally salient forms between maintenance and reintroduction. 
The data were submitted to a category (nominals vs. overt pronoun vs. null pronoun) $\times$ discourse function (referent introduction vs. referent maintenance vs. referent reintroduction) repeated measures ANOVA with group (L1 vs. L2) as a between-subject factor on the basis of mean percentages. All percentages were normalized using the arcsine transformation function. There was a main factor effect of reference form and discourse function $F(2,44)=9.404, p=.000$ ). The analysis within subjects yielded an effect of discourse function, $F(2,44)=3.649, p=.038$. Both L1 and L2 groups associate nominal categories with introduction and use null pronouns for referent maintenance. There was a substantial number of null pronouns used for reintroduction. Overt pronouns showed a mixed pattern: they were chosen for both maintenance and reintroduction. The interaction between category and discourse function was also significant $(F(4,88)=$ $6.548 ; p=.000)$. The between-subjects analysis did not detect significant differences in the overall association of reference form and discourse function; nevertheless, the distributions are not parallel, as shown in Figure 2.

\section{Discussion}

This study compared a set of narrative devices used by L1 and L2 users of LSC, in particular the use of reference forms for the third person in subject positions. Previous research on spoken languages indicates that the saliency or topicality of the referent predicts the particular pragmatic or discourse function of the referring expression used by the speaker. More salient expressions are reserved for referent introductions and less salient for maintenance. Additionally, a common finding in L2 research is the over-redundancy of L2 speakers' narrative reference forms. It has been disputed whether this is because of L1 interference from an overt pronoun language, such as in English learners of Spanish. Alternatively, it could be because of a cognitive disadvantage for L2 speakers which leads them to be more redundant. Thus, the study of L1 and L2 learners of a sign language can first of all contribute to the general study of saliency-topicality, as well as provide more cross-linguistic, indeed cross-modal data to evaluate the question of L1 influences on L2 acquisition.

Concerning the first point, the main findings of the current study were predicted from the saliency-topicality literature (Ariel, 1990, 2001; Givón, 1983; Gordon et al., 1993). For both groups, topic saliency influenced choice of reference form: nominal forms were used mainly for introductions, and null pronouns displayed an overwhelming preference for maintenance in both groups. However, a result that is at odds with our predictions based on spoken null-subject languages is that for both groups overt pronouns are more frequently linked to maintenance than to reintroduction; thus, all narratives were very explicit. Moreover, this suggests that indexical pronouns in LSC show a more flexible behaviour, being used for both reintroduction and maintenance functions. This fact indicates that they are a sort of all-purpose anaphoric expression, at least for the type of narrative discourse analysed here. For category, lexical nominals (full noun phrases (NPs), proper names, etc.) are primarily used in sign narratives for introduction, which is what is expected from such a salient reference form. But a notable proportion of them are also used to reintroduce or maintain a referent, whereas null pronouns are clearly specialized in maintenance. Overt pronouns offer, by contrast, a much less clear picture and fluctuate among the three discourse functions analysed.

As an interim summary we can say that even though the sign space is the medium for expressing reference across sentences, LSC uses its grammar to conform with general pragmatic principles for reference in narratives. What is more, these rules are in place in L2 learners of the language at an advanced stage in their bimodal bilingualism. However, closer analysis of the narratives reveals some differences in how narrative is organized between language 
modalities. LSC is more explicit than Spanish and Catalan and exhibits some differences in the distribution of forms for the different functions we focused on. Again, these specific patterns in LSC have been acquired by L2 signers despite some possible differences in the organization of the same forms in their L1 systems.

Because narratives by both groups were referentially very explicit, the majority of references used were forms that require little interpretation for their correct identification. As there is a paucity of research available on discourse patterns in sign languages it is not clear at this point if this is a general difference between signed and spoken languages, or if it is due to the particular findings of the present study. Perhaps signers are less accustomed to carrying out narrative production than speakers, meaning the signers were more concerned with being informative than speakers are with this protocol. However, both the deaf and hearing participants were explicit in their choice of forms. To put this finding in some context, Bel et al. (2010), using the same elicitation and measurement protocols, reported descriptive statistics on L1 speakers. They used only 5\% overt pronouns in Catalan narratives and 9\% for Spanish (García-Alcaraz \& Bel, 2011). In marked contrast, in the current study, $31 \%$ overt pronouns were attested for L1 signers (see Table 1). Further research is required across different genres of sign language and with more signers to confirm this result.

Since the use of overt pronouns is normally linked to a sufficiently rich context and represents a drive to ensure informativeness, we additionally explored the existence of different patterns between agreement/spatial and plain verbs. Recall that agreement verbs, but not plain ones, incorporate inflections that can identify null-subject pronominals. In the L1 narratives the different use of null pronouns with the two verb types does not appear to be major. Therefore, after calculating the proportion of null pronouns by verb type, we observed $43 \%$ of null pronouns were used with agreement/spatial verbs and $57 \%$ with plain verbs. This small difference is somewhat surprising, as if a verb carries morphology that can identify a subject, then one would expect a higher proportion of null pronouns with that verb type.

The results obtained with L2 learners show a similar pattern: $53 \%$ null pronouns appeared with agreement/spatial verbs and $47 \%$ with plain verbs. To summarize, LSC seems to differ in the distribution of pronominal forms from the spoken languages in the direct environment. This is despite the two languages being typologically similar with respect to subject realization (recall that Spanish and Catalan, like LSC, have three options for expressing subjects; namely nominals, overt pronouns and null pronouns). Comparing the L1 and L2 learner groups, both produced a similar range of narrative lengths and the general distribution of reference forms was similar for referent introduction and maintenance. The two groups also produced narratives where null pronouns and classifiers were fairly rare, again suggesting LSC is fairly referentially explicit. Thus, the advanced L2 learners after 600 hours of exposure were at a point in their acquisition where their production skills were comparable with L1 signers for length and general characteristics of narratives.

A point of caution is necessary as we point out that the current study focused only on the use of manual signs and does not describe how the face marks reference. The available research on this topic in discourse contexts is quite small but growing (Janzen, 2004; Morales-López et al., 2012) and clearly indicates that the face acts as a discourse marker in these languages. Janzen (2004) describes the role of the face and body in ASL as articulating what referents are doing over the discourse. The face can also act as a grammatical topic marker to signal that referents are changing or continuing (Janzen, 1999). The face can also be a marker of what a character might be thinking or doing in constructed action (Janzen, 2004). Non-manual features also interact with the spatial locations set up by manual signs and points. Thus, constructed action and classifiers can express different points-of-view of referents in narratives. As discourse recruits many levels of linguistic organization it is a challenge to document all of these in a single study. In this paper we describe several manual devices and show how they are used in very similar ways across modalities. In 
future research we will additionally look at how non-manual features are used (Janzen, 1999, 2004; Morales-López et al., 2012).

Turning to our second question relating to the debate on the reasons for redundancy in L2 narratives (e.g. Sorace et al., 2009), we are faced with somewhat interesting data. Both L1 and L2 signers are quite redundant in how they choose forms; however, the L2 group is even more so. It is also the case that L2 signers have acquired appropriate pragmatic choices for which reference form is suitable for each function. Yet in their production of narratives, the L1 signers are more closely following the saliency-topicality constraints. These differences are borne out in a significantly higher frequency of overt pronouns to the detriment of null pronouns among L2 signers (31\% for deaf L1 signers and 45\% for L2 learners; see Table 1). This preference, combined with the significant underproduction of null pronouns (19\% among L1 signers and 8\% among L2 learners; see Table 1), adds to the already heavy use of overt pronouns in L2 signers. Moreover, looking at the internal distribution of overt pronouns in change and continuity of reference contexts (see Figure 2), our L2 signers select overt pronouns for referent maintenance more often than L1 signers do. This result not only shows an L2 higher tolerance for redundancy but also demonstrates that overt pronominals are likely to be used in both discourse contexts, i.e. they are not associated with a single discourse function for the L2 signers.

In terms of the use of null pronouns, a number of ambiguous instances are attested. From Figure 2, we observe a notable proportion of null pronouns are used to express referent reintroduction (about 30\% among native signers and about 46\% among L2 learners). Since in topic change contexts, a null expression can refer to multiple antecedents, the use of a null pronoun can result in ambiguity. This might be interpreted as lack of control of discourse cohesion mechanisms among L2 learners, but it is somewhat surprising among native signers. Nevertheless, after reviewing the narratives the use of null subjects did not seem to disrupt communication, so we conclude that they are topics, as suggested by Lillo-Martin (1986), and consequently they remain active in the cognitive space shared by the interlocutors.

As documented for L2 learners of spoken languages, L2 signers thus produce narratives with more over-redundancy than their L1 comparison group. This finding strengthens the argument that over-redundancy is not caused by the transfer of overt subjects from the L1 (Pérez-Leroux \& Glass, 1999) as Catalan, Spanish and LSC are all null-subject languages (Lozano, 2006; Margaza \& Bel, 2006; Montrul, 2004; Sorace \& Filiaci, 2006). Reference control thus exerts a significant load on advanced users of an L2. The syntax-discourse interface is also a complex development during L1 acquisition, as evidenced by the protracted development of control of this area in child speakers and signers. It would be useful to compare older child native signers' use of discourse markers with the patterns observed in the adult L2 learners in the current study.

There are very few studies of narrative development in deaf signing children, but child signers are often under-, rather than over-explicit in their use of discourse markers. Morgan (2005) proposed some general milestones. Deaf three year olds' use of reference is unclear as referents are sometimes introduced into the story with a low information form (e.g. a role shift or classifier). Additionally, areas of sign space are not divided up for different characters appropriately, leading to interlocutor misunderstandings. For example, children might use the same location for many different referents. Between seven and 10 years, children's ability to mark reference in stories improves, but maintaining these references across long stretches of discourse is problematic. Full mastery of narrative devices is timed to occur through 11-13 years (Morgan, 2002, 2005; Morgan $\&$ Woll, 2003). While more specific comparisons need to be made it may be the case that L2 signers go through a different development of discourse mastery than child L1 signers do.

Returning to the influence of L1 on sign language learners, the spoken languages available to the LSC learners have parallel settings for the use of pronominal forms, since both can alternate 
between overt and covert subjects. As in Sorace et al. (2009), Bel et al. (2010) and García-Alcaraz and Bel (2011), we see that adult L2 learners of a signed language also adopt the strategy of avoiding ambiguities and resort to overproduction of overt forms. Thus, results from the study of L2 signing add to the argument that cognitive disadvantages among L2 learners lead to pronoun redundancy. As learners develop their bilingualism further, progress from simple sentences and start to use extended narratives for anaphoric reference, the speaker/signer has to have in mind multiple sources of information (morphosyntactic, semantic, contextual, interlocutor's assumptions and beliefs). Different types of L2 data (comprehension, experimental and acquisition) should be collected in order to confirm this idea, but we argue that signers and speakers alike need to manage all of these factors in real-time and this puts considerable processing pressure on their control of language. The outcome of this increased demand at the vulnerable interface-domain is in their choice of subject referring expressions in both modalities.

\section{Funding statement}

This research was supported by a grant to Aurora Bel from the Ministry of Science and Innovation of the Spanish Government (FFI2009-09349 \& FFI2012-35058). Gary Morgan's research was supported by the Economic and Social Research Council (Grant 620-28-600 Deafness, Cognition and Language Research Centre).

\section{References}

Ariel, M. (1990). Accessing noun-phrase antecedents. London, UK: Routledge.

Ariel, M. (2001). Accessibility theory: An overview. In T. Sanders, J. Schilperoord, \& W. Spooren (Eds.), Text representation: Linguistic and psycholinguistic aspects (pp. 29-87). Amsterdam: John Benjamins.

Arnold, J. E., Eisenband, J. G., Brown-Schmidt, S., \& Trueswell, J. C. (2000). The rapid use of gender information: Evidence of the time course of pronoun resolution from eye tracking. Cognition, 76, B13-B26.

Bamberg, M., \& Marchman, V. (1991). Binding and unfolding: Towards the linguistic construction of narrative discourse. Discourse Processes, 14, 227-305.

Barberà, G. (2010). Accessibility and space in SL discourse. Poster TISLR 10, Purdue University.

Barberà, G. (2012). The meaning of space in Catalan Sign Language (LSC): Reference, specificity and structure in signed discourse. Barcelona: Universitat Pompeu Fabra, PhD Dissertation.

Baus, C., Gutiérrez-Sigut, E., Quer, J., \& Carreiras, M. (2008). Lexical access in Catalan Sign Language (LSC) production. Cognition, 108, 856-865.

Bel, A., Perera, J., \& Salas, N. (2010). Anaphoric devices in written and spoken narrative discourse: Data from Catalan. Written Language \& Literacy, 13(2), 234-257.

Berman, R. (2008). The psycholinguistics of developing text construction. Journal of Child Language, 35: $735-771$.

Berman, R., \& Slobin, D. (1994). Relating events in narrative: A crosslinguistic developmental study. Hillsdale, NJ: Lawrence Erlbaum.

Brugman, H., \& Russel, A. (2004).Annotating multimedia/multi-modal resources with ELAN. In: Proceedings of LREC 2004. Fourth International Conference on Language Resources and Evaluation. Retrieved from http://tla.mpi.nl/tools/tla-tools/elan/

Carminati, M. (2002). Processing of Italian subject pronouns. Amherst: University of Massachusetts, $\mathrm{PhD}$ Dissertation.

Casey, S., \& Emmorey, K. (2009). Co-speech gesture in bimodal bilinguals. Language and Cognitive Processes, 24(2), 290-312.

Chamberlain, C., Morford, J. P., \& Mayberry, R. I. (2000). Language acquisition by eye. Mahwah, NJ: Lawrence Erlbaum Associates.

Cormier, K., Schembri, A., Vinson, D., \& Orfanidou, E. (2012). First language acquisition differs from second language acquisition in prelingually deaf signers: Evidence from sensitivity to grammaticality judgement in British Sign Language. Cognition, 124, 50-65. 
Emmorey, K. (2002). Language, cognition, and the brain: Insights from sign language research. Mahwah, NJ: Lawrence Erlbaum and Associates.

Emmorey, K. (2003). Perspectives on classifier constructions in sign languages. Mahwah, NJ: Lawrence Erlbaum Associates.

Emmorey, K., \& Falgier, B. (1999). Talking about space with space: Describing environments in ASL. In E. A. Winston (Ed.), Story telling and conversations: Discourse in deaf communities (pp. 3-26). Washington, DC: Gallaudet University Press.

Emmorey, K., \& Falgier, B. (2004). Conceptual locations and pronominal reference in American sign language. Journal of Psycholinguistic Research, 33(4), 321-331.

Emmorey, K., Norman, F., \& O'Grady, L. (1991). The activation of spatial antecedents from overt pronouns in American sign language. Language and Cognitive Processes, 6(3), 207-228.

Emmorey, K., Petrich, J. A. F., \& Gollan, T. H. (2012). Bilingual processing of ASL-English code-blends: The consequence of accessing two lexical representations simultaneously. Journal of Memory and Language, 67(1), 199-210.

Emmorey, K., Tversky, B., \& Taylor, H. (2000). Using space to describe space: Perspective in speech, sign, and gesture. Spatial cognition and computation, 2, 157-180.

García-Alcaraz, E., \& Bel, A. (2011). Selección y distribución de los pronombres en el español L2 de los hablantes de árabe. Revista de Lingüistica y Lenguas Aplicadas, 6, 165-179.

Garvey, C., Caramazza, A., \& Yates, J. (1976). Factors influencing assignment of pronoun antecedents. Cognition, 3, 227-243.

Gee, J., \& Kegl, J. (1983). Narrative/story structure, pausing, and American sign language. Discourse Processes, 6, 243-258.

Givón, T. (Ed.) (1983). Topic continuity in discourse: A quantitative cross-language study. Amsterdam: John Benjamins.

Gordon, P. C., Grosz, B. J., \& Gilliom, L. A. (1993). Pronouns, names, and the centering of attention in discourse. Cognitive Science, 17, 311-347.

Hendriks, H. (Ed.) (2005). The structure of learner varieties. Berlin/New York: Mouton de Gruyter.

Hendriks, P., Koster, C., \& Hoeks, J. (2013). Referential choice across the lifespan: Why children and elderly adults produce ambiguous pronouns. Language and Cognitive Processes.

Hickmann, M. (2004). Coherence, cohesion, and context: Some comparative perspectives in narrative development. In S. Strömqvist, \& L. Verhoeven (Eds.), Relating events in narrative: Typological and contextual perspectives (pp. 282-306). Mahwah: Lawrence Erlbaum.

Janzen, T. (1999). The grammaticalization of topics in American sign language. Studies in Language, 23(2), 271-306.

Janzen, T. (2004). Space rotation, perspective shift, and verb morphology in ASL. Cognitive Linguistics, 15(2), 149-174.

Jarvis, S., \& Pavlenko, A. (2008). Crosslinguistic influence in language and cognition. New York: Routledge.

Klima, E. S., \& Bellugi, V. (1979). The signs of language. Cambridge, MA: Harvard University Press.

Lillo-Martin, D. (1986). Two kinds of null arguments in American sign language. Natural Language and Linguistic Theory, 4, 415-444.

Lillo-Martin, D., \& Quadros, R. M. (2011) Acquisition of the syntax-discourse interface: The expression of point of view. Lingua, 121(4), 623-636.

Lozano, C. (2006). The development of the syntax-discourse interface: Greek learners of Spanish. In V. Torrens, \& L. Escobar (Eds.), The acquisition of syntax in Romance languages (pp. 371-399). Amsterdam: John Benjamins.

MacSweeney, M., Capek, C. M., Campbell, R., \& Woll, B. (2008). The signing brain: The neurobiology of sign language. Trends in Cognitive Sciences, 12(11), 232-240.

Margaza, P., \& Bel, A. (2006). Null subjects at the syntax-pragmatics interface: Evidence from Spanish interlanguage of Greek speakers. In M. Grantham O’Brien, C. Shea, \& J. Archibald (Eds.), Proceedings of the 8th generative approaches to second language acquisition conference (pp. 88-97). Somerville, MA: Cascadilla. 
Metzger, M. (1994). Constructed dialogue and constructed action in American sign language. In C. Lucas (Ed.), Sociolinguistics in deaf communities (pp. 255-271). Washington, DC: Gallaudet University Press.

Meurant, L. (2008). Role shift, anaphora and discourse polyphony in sign language of Southern Belgium (LSFB). In J. Quer (Ed.), Signs of the time. Selected papers from TISLR 8. Hamburg: Signum Verlag.

Montanari, S. (2002). The development of narrative competence in the L1 and L2 of Spanish-English bilingual children. International Journal of Bilingualism, 8(4), 449-497.

Montrul, S. (2004). Subject and object expression in Spanish heritage speakers: A case of morphosyntactic convergence. Bilingualism: Language and Cognition, 7(2), 125-142.

Morales-López, E., Reigosa-Varela, C., \& Bobillo-García, N. (2012). Word order and informative functions (topic and focus) in Spanish signed language utterances. Journal of Pragmatics, 44, 474-489.

Morgan, G. (2002). The encoding of simultaneity in children's BSL narratives. Journal of Sign Language and Linguistics, 5(2), 127-161.

Morgan, G. (2005). The development of narrative in British sign language. In B. Schick, M. Marschark, \& P. Spencer (Eds.), Advances in sign language development in deaf children. Oxford: Oxford University Press.

Morgan, G., \& Woll, B. (Eds.). (2002). Directions in sign language acquisition. Amsterdam: Benjamins.

Morgan, G., \& Woll, B. (2003). The development of reference switching encoded through body classifiers in British sign language. In K. Emmorey (Ed.), Perspectives on classifier constructions in sign languages (pp. 297-310). Mahwah, NJ: Lawrence Erlbaum.

Morgan, G., \& Woll, B. (Eds.) (2007). Understanding signed language classifiers a polycomponential approach. Lingua, 117(7), 1159-1168.

Müller, N., \& Hulk, A. (2001). Crosslinguistic influence in bilingual language acquisition: Italian and French as recipient languages. Bilingualism: Language and Cognition, 4 (1), 1-21.

Neidle, C., Kegl, J., MacLaughlin, D., Bahan, B., \& Lee, R. (2000). The syntax of American sign language: Functional categories and hierarchical structure. Cambridge, MA: MIT Press.

Pérez-Leroux, A. T., \& Glass, W. R. (1999). Null anaphora in Spanish second language acquisition: Probabilistic versus generative approaches. Second Language Research, 15, 220-249.

Perniss, P. (2012). Use of sign space. In R. Pfau, M. Steinbach, \& B. Woll (Eds.), Sign language: An international handbook (pp. 412-431). Berlin: Mouton De Gruyter.

Petitto, L. A. (1997). In the beginning: On the genetic and environmental factors that make early language acquisition possible. In M. Gopnik (Ed.), The inheritance and innateness of grammars (pp. 45-69). England: Oxford University Press.

Pyers, J., \& Emmorey, K. (2008). The face of bimodal bilingualism: ASL grammatical facial expressions are produced when bilinguals speak to English monolinguals. Psychological Science, 19, 531-535.

Quadros, R. M. de (1999). Phrase structure of Brazilian sign language. PhD Dissertation. PUC/RS, Porto Alegre.

Quer, J. (2011a). La llengua de signes catalana, una llengua pròpia més de Catalunya. Catalan Review, 25, $45-57$.

Quer, J. (2011b). When agree to disagree is not enough: Further arguments for the linguistic status of sign language agreement. Theoretical Linguistics, 37(3-4), 189-196.

Sandler, W. \& Lillo-Martin, D. (2006). Sign Language and Linguistic Universals. Cambridge, UK: Cambridge University Press.

Schick, B., Marschark, M., \& Spencer, P.E. (2006) (Eds) Advances in Sign Language Development in Deaf Children. Oxford University Press.

Serratrice, L. (2006). Referential cohesion in the narratives of bilingual English-Italian children and monolingual peers. Journal of Pragmatics, 39, 1058-1087.

Shin, N. L., \& Cairns, H. S. (2012). The development of NP selection in school-age children: Reference and Spanish subject pronouns. Language Acquisition: A Journal of Developmental Linguistics, 19(1), 3-38.

Sorace, A. (2011). Pinning down the concept of "interface" in bilingualism. Linguistic Approaches to Bilingualism 1-33

Sorace, A., \& Filiaci, F. (2006). Anaphora resolution in near-native speakers of Italian. Second Language Research, 22(3), 339-368. 
Sorace, A. and Serratrice, L. (2009). Internal and external interfaces in bilingual language development: Beyond structural overlap. International Journal of Bilingualism 13: 195-210.

Sorace, A., Serratrice, L., Filiaci, F., \& Baldo, M. (2009). Discourse conditions on subject pronoun realization: Testing the linguistic intuitions of older bilingual children. Lingua, 119, 460-477.

Stokoe, W. (1960). Sign language structure: An outline of the visual communication systems of the American deaf. Studies in Linguistics Occasional Papers, 8, 1-78.

Strömqvist, S., \& Day, D.(1989). The development of discourse cohesion. An asymmetry between child L1 and adult L2 acquisition. Göteborg Papers in Theoretical Linguistics, 56, 1-24.

Strömqvist, S., \& Verhoeven, L. (Eds.) (2004). Relating events in narrative: Vol. 2. Typological and contextual perspectives. Mahwah, NJ: Lawrence Erlbaum Associates.

Sutton-Spence, R., \& Woll, B. (1999). The linguistics of British sign language. An introduction. Cambridge: Cambridge University Press.

Tang, G., \& Sze, F. (2002). Nominal expressions in Hong Kong sign language: Does modality make a difference? In R. Meier, K. Cormier, \& D. Quinto-Pozos (Eds.), Modality and structure in signed and spoken language (pp. 296-320). Cambridge: Cambridge University Press.

Thompson, R. L., Emmorey, K., \& Kluender, R. (2006). The relationship between eye gaze and agreement in American sign language: An eye-tracking study. Natural Language \& Linguistic Theory, 24, 571-604.

Trueswell, J. C., Papafragou, A., \& Choi, Y. (2011). Syntactic and referential processes: What develops? In E. Gibson, \& N. Pearlmutter (Eds.), The processing and acquisition of reference (pp. 65-108). Cambridge, MA: MIT Press.

Tsimpli, I. M., Sorace, A., Heycock, C., \& Filiaci, F. (2004). First language attrition and syntactic subjects: A study of Greek and Italian near-native speakers of English. International Journal of Bilingualism, 8 , 257-277.

Wilbur, R. (1994). Eye blinks and ASL phrase structure. Sign Language Studies, 84, 221-240.

\section{Author biographies}

Aurora Bel is Associate Professor at the Universitat Pompeu Fabra. Her research interests and publications deal with the relationship between linguistic theory and first and second language acquisition, as well and bilingualism, in multilingual environments and different populations (children, adolescents and adults). She has a co-authored book entitled A Portrait of the Young in the New Multilingual Spain (2008).

Marta Ortells is a graduate master student from the Universitat Pompeu Fabra in Theoretical and Applied Linguistics with the specialization in sign language acquisition. As a Catalan Sign Language (LSC) interpreter, she is currently involved in the deaf community where she also creates teaching materials for LSC.

Gary Morgan is Professor of Psychology at City University London. He has published widely on sign language acquisition, cognitive development, and psycholinguistic studies of sign languages and gestures. He is the co-author of Directions in Sign Language Acquisition (2002), The Signs of a Savant (2010) and Research Methods in Sign Language Studies: A Practical Guide (in press).

\section{Appendix I}

\section{Examples of coding:}

(1) a. Null (__ ) and overt pronoun (IX3) as $\underline{\mathbf{R M}}$ (example from a deaf native):

IX3 3 3-LOOK-1

He looked at me and i -UNDERSTAND-1 WRONG IX3 $\mathbf{3}_{\mathrm{i}}$ CALL TEACHER misunderstood me. He called the teacher

b. Overt pronoun (IX3) as $\underline{\mathbf{R} \mathbf{R}}$ (example from an L2 speaker):

IX3 $_{\mathrm{i}}$ 3-EXPLAIN-1PLU EXAM FIRST-TIME MONTH AFTER mc IX1-PLU OK BE- AGREE IX $\mathbf{3}_{\mathrm{i}}$ GO 
He explained us that the first exam would take place next month. We all agreed. He left

c. Null pronoun ( ) as $\underline{\mathbf{R M}}$ (L2 speaker):

IX3 ${ }_{i}$ 3-EXPLAIN-1 TOPIC TRICK CRIB [...]ALSO EXPLAIN-1 TRICK OTHER

He explained me a crib's trick $[\ldots] \_$_... also explained me another trick

d. Overt pronoun (IX3) as redundant $\underline{\mathbf{R M}}$ (example from an L2 speaker):

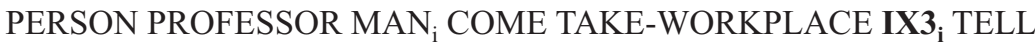

The teacher came back to his workplace and he told 